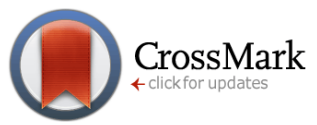

*For correspondence:

tafazolim@mums.ac.ir

Competing interests: The authors declare that no competing interests exist.

Received: 05 September 2016 Accepted: 03 November 2016 Published: 10 November 2016

Copyright The Author(s) 2016. This article is published with open access by BioMedPress (BMP).

This article is distributed under the terms of the Creative Commons Attribution License (CC-BY 4.0) which permits any use, distribution, and reproduction in any medium, provided the original author(s) and the source are credited.

\title{
Comparing the effect of breastfeeding promotion interventions on exclusive breastfeeding: an experimental study
}

\section{Asieh Moudi ${ }^{1}$, Mahin Tafazoli ${ }^{2}{ }^{*}$, Hasan Boskabadi ${ }^{3}$, Saeed Ebrahimzadeh ${ }^{4}$, Hamid Salehiniya ${ }^{5}$}

\author{
${ }^{1}$ Birjand University of Medical Sciences, Birjand, Iran \\ ${ }^{2}$ Evidence Based Care Research Center, Department of Midwifery, School of Nursing \\ and Midwifery, Mashhad University of Medical Sciences, Mashhad, Iran \\ ${ }^{3}$ Neonatal Research Center, Department of Neonatology, School of Medicine, Mashhad \\ University of Medical Sciences, Mashhad, Iran \\ ${ }^{4}$ Department of Medical Surgical Patient Care, School of Nursing and Midwifery, \\ Mashhad University of Medical Sciences, Mashhad, Iran \\ ${ }^{5}$ Zabol University of Medical Sciences, Zabol, Iran And, Department of Epidemiology \\ and Biostatistics, School of Public Health, Tehran University of Medical Sciences, Tehran, \\ Iran
}

\section{Abstract}

Introduction: Despite the proven risks associated with not breastfeeding, few mothers exclusively breastfeed their babies for six months as recommended by the World Health Organization. This study was conducted to compare the effect of breastfeeding promotion interventions on exclusive BMF among primiparous women. Methods: This quasi-experimental study was conducted on a sample of 93 primiparous women who were referred to health care centres, Mashhad, Iran, in 2010. Health care centres were selected by multistage sampling method, and then randomly allocated into two intervention groups (peer support group and health care provider's education group) and one control group. Primigravidae aged 18-35 years old, with singleton pregnancy, with gestational age of 35-36 weeks, and intending to breastfeed their children were randomly selected out of health care centres. The peer support group participants received supports from their peers four times and education group's participants received 4 training sessions by health care providers. The control group received only routine cares. Exclusive BMF duration and rate assessed at 4 and 8 weeks postpartum and collected data were analysed using SPSS (ver.11.5) software. 
Results: There were no significant differences in exclusive BMF duration at 4 and 8 weeks among the 3 groups $(P=0.993, P=0.904)$. Exclusive BMF rate at 4 and 8 weeks after birth was significantly different among the 3 groups $(P=0.043, P=0.023)$. No significant difference was found between peer support and healthcare provider's education groups with respect to BMF rate at 4 weeks $(P=0.111)$, but the difference was significant at 8 weeks ( $P=0.027)$. Conclusion: All women should be offered education and peer support to breastfeed their babies to increase the exclusive breastfeeding rate. But to continue exclusive breastfeeding, and increase its duration, help of family is more important than education and peer support. Support that is only offered reactively, in which women are expected to initiate the contact, is unlikely to be effective; women should be offered ongoing support so they can predict that support will be available. Support should be tailored to the needs of the setting and the population group.

\section{Keywords}

Peer Support, Education, Health Care Providers, Exclusive Breast Feeding

\section{Introduction}

World Health Organization ( $\mathrm{WHO}$ ) recommended exclusive breast milk feeding (BMF) to the infant for the first six months of life to achieve optimal growth, development, 911 and health. Nevertheless, exclusive BMF remains uncommon in most countries (both developed and developing), even in countries with high rates of breastfeeding initiation (Imdad et al., 2011). Recent data shows that the prevalence of exclusive BMF in developing countries has increased from 33\% in 1995 to just 39\% in 2010 (Haroon et al., 2013). Although using promoting programs, exclusive BMF has had a descending trend in Iran in 2000-2006, and an increasing trend in 2007-2011 (Motlaq Me, 2013). According to the results of the Demographic Health Survey (2000) (Olang et al., 2009), less than $45 \%$ of the infants who were younger than 6 months used exclusive BMF decreasing the rate to 27\% in 2004 (Olang et al., 2009) and 23.1\% in Integrated Monitoring Evaluation System Survey in 2006 (Esfahani Mm, 2009), but fortunately, prevalence of exclusive BMF increased to 53.1\% in 2011 (Motlaq Me, 2013). Integrated Monitoring Evaluation System Survey in Razavi Khorasan Province, Iran showed that the prevalence of exclusive BMF was approximately $25 \%$ (Esfahani Mm, 2009).

BMF is natural, but it requires skill and education. Especially in primiparous women, limited information and inexperience about breastfeeding is the most common problem. This may lead to vicious ring of problems which may end in failure of establishment and continuation of breastfeeding (Najem, 2011; Translators-Group, 2008). 
WHO declared BMF promotion and support as a public health priority in 2003 following reduction in the rate and duration of exclusive BMF (Esfahani Mm, 2009). In order to achieve this, two vast groups of hospital and communityconcentrated strategies, which will be done by professional and nonprofessional people, are recommended to promote exclusive BMF (2006, July 21).

One of the hospital-concentrated strategies is fulfilling educational programs by professionals (Translators-Group, 2008). BMF education is usually a formalised, defined, descriptive, and goal-oriented programme with a specific purpose and target audience, and given as part of routine antenatal care (Lumbiganon et al., 2012).

Breastfeeding education provided by the primary care physician during routine preventive visits is likely to have limited impact, compared with the effects of various barriers that negatively affect breastfeeding duration such as psychological factors, cultural factors, and returning to work. Studies have documented that infant feeding counselling is often associated with poor quality or unavailability for many women (Ansari et al., 2014; Owais Ahmad M, 2012). Although there is an education regarding exclusive breastfeeding during pregnancy by midwives in Iran, it did not result in great success in breastfeeding (Ansari et al., 2014).

Dyson's review study have shown that formal and informal education, based on the requirements, are effective in increasing BMF (Dyson et al., 2005). Belay showed that prenatal education could increase exclusive BMF rate (Belay and Haidar, 2013). Ansari reported that educational program could increase exclusive BMF duration (Ansari et al., 2014). Likewise, Artieta-Pinedo believes that antenatal education might increase breastfeeding for first month after birth (Artieta-Pinedo et al., 2013).

On the other hand, peer support is an important element in offering health care (Dennis, 2003), and community education and support for target population (Mickens, 2008). Peer support in BMF includes emotional support, encouragement, BMF education, and help in resolving nursing mothers' difficulties by mothers who have had a BMF history (Mead et al., 2001; Muller et al., 2009). Peer support can be done during pregnancy and postpartum by an individual, one-to-one counselling, a support group, a phone call or a home visit (Dennis, 2003; Mead et al., 2001; Mickens, 2008) or a peer who is similar to the nursing mother in some special characteristics like age, sex, occupation, socioeconomic status, health status, etc (Dennis, 2003; Muller et al., 2009). Several studies have shown the effect of peer support on increasing early BMF initiation, its continuation up to 6-8 weeks, increasing the rate (Andrade S, 2008; Chung et al., 2008; Dennis et al., 2002; Dennis, 1999; Dennis and Kingston, 2008; Mickens, 2008; Palda et al., 2004) and duration of exclusive BMF (Andrade S, 2008; Dennis, 1999; Dennis and Kingston, 2008; Meglio et al., 2010; Palda et 
al., 2004; Persad and Mensinger, 2008) and decreasing BMF problems (Mickens, 2008; Rossman, 2007).

Although several studies have shown the effectiveness of support and education for nursing mothers by professionals or non-professionals on all patterns of infant feeding (exclusive, predominant, complete, and partial) (Chung et al., 2008; Sikorski et al., 2003), especially exclusive BMF (Sikorski et al., 2003), but in relation to breastfeeding promotion, there is little information as to which type of strategies are most effective in promoting exclusive breastfeeding and achieving high and equitable coverage (Chung et al., 2008; Sikorski et al., 2003). Therefore, this study is aimed at comparing the effect of breastfeeding promotion interventions on exclusive BMF in primiparous women settled in Mashhad, a city in the North East of Iran, in 2010.

\section{Methods}

\section{Design and participants}

This quasi-experimental study was conducted on 108 primigravidae who were referred to health care centres in Mashhad in 2010. Research ethics approval has been obtained from Mashhad University of Medical Sciences (No: 12-082) on September 24, 2010. All pregnant women participated and peer supports were requested to give their written informed consent prior to any study procedure. To secure confidentiality, all identifying information of participants, including name, medical, and contact information as well as all collected data will be kept in patient's privacy.

Multistage sampling was done. First, the city of Mashhad was divided into three clusters. Each cluster contained a health centre, which consisted of 40 to 60 small health centres. In every cluster, a list of all health centres was prepared using random numbers table, and finally three health centres were randomly selected. The selected centres were randomly assigned into 3 groups of peer support, education by health care providers, and control. A total of 9 health centres were included in the study.

The research was conducted in three stages, including peer selection and training, selection and training of the health care providers, and sample selection and intervention.

\section{Peer selection and training}

In the first stage, among the people covered by health care centres dedicated to the peer support group, 23 Iranian female volunteers living in Mashhad, with at least a fifth grade education, a BMF history, and good attitude towards BMF, were selected through a public invitation. Then, their knowledge and attitude 
towards BMF and communication skills were tested using a pre-test by researcher.

To prepare volunteers for support, the researcher held training classes in five group sessions with 7 to 8 persons in each group. Daily sessions over 3 hours with a 45-minute break was held every 90 minutes separately by the investigator at each centre.

The education was on the definition of peer support; that is, the purpose, role, and responsibilities of peer volunteers; communication skills; and the basics of BMF (including the benefits of BMF; the anatomy and physiology of lactation; conditions of feeding and breast insertion; proper establishment of BMF; barriers to support and encourage; questions, common concerns, and stories; and false beliefs about BMF), in the mentioned health care with the lecture approach, using educational slides and images, questions and answers, and role playing. Sixteen out of the twenty three enrolled participants completed the course, and obtained at least $75 \%$ of the post-test scores of knowledge, attitude, and communication skills and 75 percent of the self-assessment score, and took responsibility as a peer to support introduced mothers.

\section{Selection and training of the health care providers}

In the second stage, 7 midwives were selected among official or contract healthcare providers who had passed BMF counselling classes, and employed in health care centres allocated to health care provider's education group. After obtaining written consent, in order to integrate the presented materials to the participants, they received necessary education for 2 hours according to BMF education guide for mothers.

\section{Sample selection and intervention}

After education of the peers and health care providers, the sample size was calculated with a pilot study. At first, 30 pregnant women with eligibility criteria were randomly divided into three groups of peer support (10), education by health care providers $(n=10)$, and control $(n=10)$.

Sample size was calculated on the basis of the results of pilot study and using the formula for the difference between three means with the following assumption of $3.8 \pm 2.66$ days duration of exclusive breastfeeding. We estimated that a sample of 27 mothers in each group would have $85 \%$ power with a 2 tailed $\alpha$ error of $<0.05$ to detect a 21.8 relative increase in the duration of exclusive breastfeeding at 8 weeks.

We assumed that nearly $30 \%$ of mothers would be lost to follow-up monitoring; therefore, we planned to include 36 eligible mothers in each group. At last 108 women were enrolled the study. 
Inclusion criteria were as follows: Iranian primigravidae who were 18-35 years old, living in Mashhad with at least a fifth-grade education, normal BMI, singleton pregnancy, and intended to breast-feed their children with gestational age between 35-36 weeks.

The researcher referred to the selected health care centres, and prepared a list of eligible pregnant women from the office of maternal care; then, 12 participants were randomly selected at each using a random number table centre. The eligible women were invited by phone to the health centres. After explaining the objectives and the application of research results, they were enrolled, and informed consent was obtained from them.

Selected mothers in the centre assigned to the peer support were introduced to a peer volunteer with regard to cultural, social, and economical similarities, by the researcher or similar coordinated peer. The first support was conducted at 36-38 weeks of pregnancy, and three latter supports in 1, 2 and 3 interval weeks after birth, by peer. The first and third supports were done by face to face, and second and fourth supports by phone.

Selected mothers in the centre assigned to the training health care providers received the first training at 36-38 weeks of pregnancy, and three latter training sessions in 1, 2 and 3 interval weeks after birth by health care provider. The first and third training sessions were done by face to face, and second and fourth by phone.

Selected mothers in the centre assigned to the control just received routine prenatal (including nursing training in 35-37 weeks of pregnancy) and postpartum care (including nursing training in $1-3,10-15$ and $42-60^{\text {th }}$ day postpartum).

\section{Instruments}

Attitude of peer volunteers, health care providers, and pregnant women towards breastfeeding was evaluated by a 20 -question questionnaire. The responses were based on 3-point Likert scale (agree, no idea, and disagree) with score of 1 to 3; the minimum score was 20 and the highest score 60 . In other words, attitude was classified as poor (20-33.3), moderate (33.4-46.6), and good 46.7-60). Content validity and reliability were confirmed using the Cronbach's Alpha coefficient of 0.74 . The feeling of mother and husband towards pregnancy was examined with a 5-point Likert-type scale as, "very happy", "happy", "indifferent", "sad", and "very sad".

Baseline characteristics regarding mother and her pregnancy were gathered using a questionnaire at the beginning of the study. Baseline characteristics regarding delivery and infant were gathered using a questionnaire during postpartum period. Breast milk feeding information was gathered by a daily reporting questionnaire form on infant nutrition during 8 weeks after postpartum. Exclusive BMF duration and rate were assessed at 4 and 8 weeks 
postpartum. The daily reporting questionnaire was approved by 13 faculty members in Mashhad University of Medical Sciences with content validity and reliability with test-retest reliability $(r=0.9)$ and Cronbach's alpha $(r=0.7)$.

\section{Statistical analysis}

SPSS (version 11.5, SPSS, Inc, Chicago, IL, USA) software package was used for all statistical analyses. Normality of quantitative variables was evaluated by Kolmogorov-Smirnov test. Quantitative variables have been presented as mean and standard deviation, and qualitative variables as number and percent. The main dependent variables were exclusive BMF duration and rate at 4 and 8 weeks postpartum. The analysis of variance (ANOVA) test was used to compare mother's age and birth weight of newborn among groups. The Kruskal Wallis test was used to compare participant's education and occupation, the first time of BMF, participant's feeling towards pregnancy, the first prenatal care visit, spouse's idea about BMF, others' idea about BMF, location of prenatal care among groups. The chi-square was used to compare delivery mode, spouse's feeling toward pregnancy, assistant person in caring infant after birth among groups. The Fisher exact test was used to compare family income, unplanned pregnancy among groups. The chi-square was used to compare exclusive BMF rates among groups at 4 and 8 weeks postpartum, and exclusive BMF rates between 4 and 8 weeks were compared in each group using McNemar test. The ANOVA was used to compare exclusive BMF duration among groups at 4 and 8 weeks postpartum. Exclusive BMF duration between 4 and 8 weeks were compared in each group using paired t-test. Confidence coefficient $95 \%$ and $\alpha$ level of 0.05 were used for all statistical tests.

\section{Results}

Sixteen out of the 23 enrolled peer supporters completed the educational course. Their mean age was $34.7 \pm 6.36$, most of the women had 2 children (50\%), the mean duration of BMF for children was $21.3 \pm 5.51$ months, and majority of them had elementary (37.5\%) and high school (37.5\%) education.

The average age and work experience of health care providers participated were $33.6 \pm 4.40$ and $7.9 \pm 3.98$ years, respectively.

Fifteen women out of 108 participants were excluded because of the exclusion criteria during the research such as being hospitalised, neonatal death or still birth, lack of tendency to keep cooperation, or not receiving education or support (Fig. 1). So the analyses were performed on 93 participants. There were no differences in baseline characteristics regarding maternal and infant data between the 3 groups such as participant's age, birth weight (Table 1), education, occupation, family income, planned pregnancy, when to decide for BMF, delivery mode, and the first time of BMF (Table 2). However, three groups 
had significant differences in some variables like participant's feeling toward pregnancy $(P=0.039)$, spouse's feeling about pregnancy $(P=0.009)$, prenatal care for the first time $(P=0.002)$, the spouse's attitude towards breast milk feeding $(P=0.038)$, the others' attitude towards breast milk feeding $(P=0.022)$, place of prenatal care $(P=0.029)$, and assistant help in child care at and after birth $(P=0.023)$ (Table 3). The effect of these variables was analysed on two dependent variables (duration and rate of exclusive BMF). None of the heterogeneous variables affect the duration and rate of exclusive BMF except assistant help in child care at and after birth; which just affected the duration of exclusive BMF and not its rate (Table 3 ).

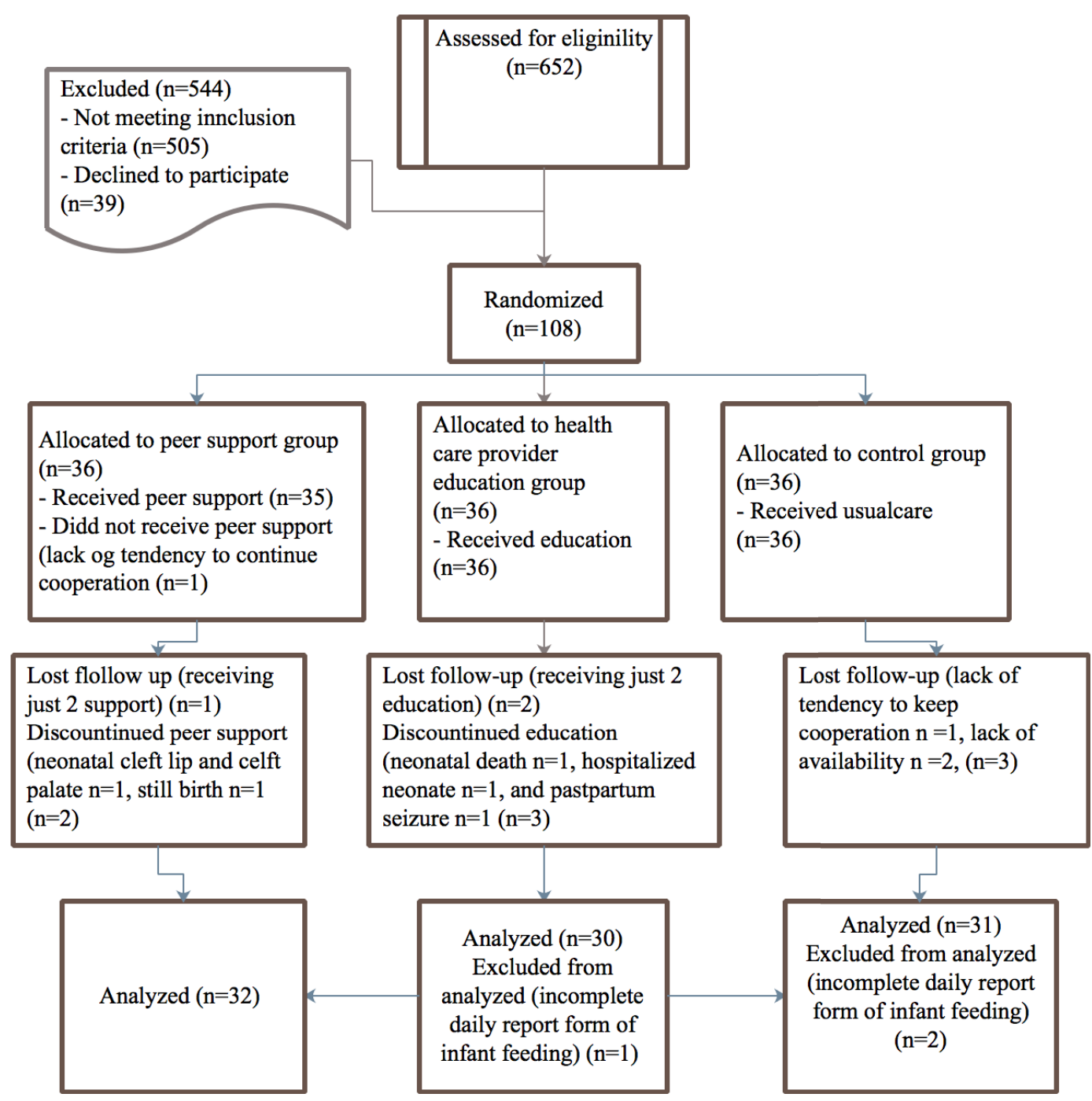

Figure 1. Consort flow diagram. Enrollment, Allocation, Follow-Up patients in the study. 
Table 1. Mean of participants' age and birth weight of newborn in assessed groups

\begin{tabular}{|l|l|l|l|l|}
\hline \multicolumn{1}{|c|}{ Variable } & \multicolumn{3}{|c|}{ Group } & P \\
\cline { 2 - 5 } & Peer support & $\begin{array}{c}\text { Health care } \\
\text { provider's } \\
\text { education }\end{array}$ & Control & \\
\hline & Mean \pm SD & Mean \pm SD & Mean \pm SD & \\
\hline Mother's age (year) & $24.0 \pm 3.78$ & $24.3 \pm 3.85$ & $23.0 \pm 4.06$ & 0.389 \\
\hline Birth weight of newborn $(\mathrm{kg})$ & $3.19 \pm 0.394$ & $3.24 \pm 0.452$ & $3.38 \pm 0.387$ & 0.189 \\
\hline
\end{tabular}

Table 2. Education, occupation, family income, unplanned pregnancy, delivery mode, and the first time of BMF in assessed groups

\begin{tabular}{|c|c|c|c|c|c|c|c|c|}
\hline \multirow{3}{*}{\multicolumn{2}{|c|}{ Varibale }} & \multicolumn{6}{|c|}{ Groups } & \multirow[t]{3}{*}{ Test results } \\
\hline & & \multicolumn{2}{|c|}{$\begin{array}{l}\text { Peer } \\
\text { support }\end{array}$} & \multicolumn{2}{|c|}{$\begin{array}{l}\text { Health care } \\
\text { provider's } \\
\text { education }\end{array}$} & \multicolumn{2}{|c|}{ Control } & \\
\hline & & $\mathbf{N}$ & $\%$ & $\mathbf{N}$ & $\%$ & $\mathbf{N}$ & $\%$ & \\
\hline \multirow[t]{4}{*}{ Education } & Basic & 1 & 3.1 & 1 & 3.3 & 3 & 9.7 & \multirow{4}{*}{$\begin{array}{c}x^{2}=3.787 \\
d f=2 \\
P=0.151\end{array}$} \\
\hline & Junior high school & 7 & 21.9 & 6 & 20.0 & 11 & 35.5 & \\
\hline & High school & 17 & 53.3 & 18 & 60.0 & 13 & 41.9 & \\
\hline & Academic & 7 & 21.9 & 5 & 16.7 & 4 & 12.9 & \\
\hline \multirow[t]{3}{*}{ Ocupation } & Homemaker & 29 & 90.6 & 25 & 83.3 & 27 & 87.1 & \multirow{3}{*}{$\begin{array}{c}x^{2}=0.020 \\
d f=4 \\
P=0.762\end{array}$} \\
\hline & Student & 1 & 3.1 & 1 & 3.3 & 0 & 0 & \\
\hline & Employed & 2 & 6.3 & 4 & 13.3 & 4 & 12.9 & \\
\hline \multirow{2}{*}{$\begin{array}{l}\text { Family } \\
\text { income }\end{array}$} & Inadequate & 5 & 15.6 & 3 & 10.0 & 2 & 6.5 & \multirow{2}{*}{$\begin{array}{c}X^{2}=1.392 \\
d f=2 \\
P=0.499\end{array}$} \\
\hline & Adequate & 27 & 84.4 & 27 & 90.0 & 29 & 93.5 & \\
\hline \multirow{2}{*}{$\begin{array}{l}\text { Unplanned } \\
\text { prenancy }\end{array}$} & Yes & 3 & 9.4 & 5 & 16.7 & 3 & 9.7 & \multirow{2}{*}{$\begin{array}{c}x^{2}=0.996 \\
d f=2 \\
P=0.665\end{array}$} \\
\hline & No & 29 & 90.6 & 25 & 83.3 & 28 & 90.3 & \\
\hline \multirow{2}{*}{$\begin{array}{l}\text { Delivery } \\
\text { mode }\end{array}$} & NVD & 16 & 50.0 & 11 & 36.7 & 18 & 58.1 & \multirow{2}{*}{$\begin{array}{c}X^{2}=2.846 \\
d f=2 \\
P=0.241\end{array}$} \\
\hline & CS & 16 & 50.0 & 19 & 63.3 & 13 & 41.9 & \\
\hline \multirow[t]{3}{*}{$\begin{array}{l}\text { The first } \\
\text { time of BMF }\end{array}$} & $\begin{array}{l}\text { First half an hour } \\
\text { after birth }\end{array}$ & 7 & 22.6 & 5 & 16.7 & 6 & 19.4 & \multirow{3}{*}{$\begin{array}{c}x^{2}=0.258 \\
d f=2 \\
P=0.879\end{array}$} \\
\hline & $\begin{array}{l}30-60 \text { min after } \\
\text { birth }\end{array}$ & 7 & 22.6 & 7 & 23.3 & 7 & 22.6 & \\
\hline & 1-24hr after birth & 17 & 54.8 & 18 & 60.0 & 18 & 58.1 & \\
\hline
\end{tabular}


Table 3. Heterogeneous variables and their effect on the duration and rate of exclusive BMF in assessed groups

\begin{tabular}{|c|c|c|c|c|c|c|c|c|c|c|c|}
\hline \multirow[t]{3}{*}{ Variable } & \multicolumn{6}{|c|}{ Groups } & \multirow{3}{*}{$\begin{array}{c}\text { Test } \\
\text { results }\end{array}$} & \multicolumn{4}{|c|}{ Variable effects on exclusive BMF } \\
\hline & \multicolumn{2}{|c|}{ Peer support } & \multicolumn{2}{|c|}{$\begin{array}{c}\text { Health Care } \\
\text { provider's } \\
\text { education }\end{array}$} & \multicolumn{2}{|c|}{ Control } & & \multicolumn{2}{|c|}{ Rate of EBMF } & \multicolumn{2}{|c|}{ Duration of EBMF } \\
\hline & $\mathbf{N}$ & $\%$ & $\mathbf{N}$ & $\%$ & $\mathbf{N}$ & $\%$ & & 4 wks & 8 wks & 4 wks & 8 wks \\
\hline \multirow{4}{*}{$\begin{array}{l}\text { Participant } \\
\text { 's feeling } \\
\text { toward } \\
\text { pregnancy }\end{array}$} & Very pleased & 13 & 40.6 & 4 & 13.3 & 10 & \multirow{4}{*}{$\begin{array}{c}x^{2}=6.465 \\
d f=2 \\
P=0.039\end{array}$} & \multirow{4}{*}{$\begin{array}{c}x^{2}=2.539 \\
d f=3 \\
P=0.506\end{array}$} & \multirow{4}{*}{$\begin{array}{c}x^{2}=2.801 \\
d f=3 \\
P=0.372\end{array}$} & \multirow{4}{*}{$\begin{array}{c}x^{2}=2.957 \\
d f=3 \\
P=0.398\end{array}$} & \multirow{4}{*}{$\begin{array}{c}x^{2}=2.899 \\
d f=3 \\
P=0.407\end{array}$} \\
\hline & Pleased & 18 & 56.3 & 22 & 73.3 & 18 & & & & & \\
\hline & Neutral & 0 & 0 & 3 & 10.0 & 2 & & & & & \\
\hline & Sad & 1 & 3.1 & 1 & 3.3 & 1 & & & & & \\
\hline \multirow{2}{*}{$\begin{array}{c}\text { Spouse's } \\
\text { feeling } \\
\text { toward } \\
\text { pregnancy }\end{array}$} & Very pleased & 19 & 59.4 & 7 & 23.3 & 17 & \multirow{2}{*}{$\begin{array}{c}x^{2}=9.47 \\
d f=2 \\
P=0.009\end{array}$} & \multirow{2}{*}{$\begin{array}{c}x^{2}=0.164 \\
d f=1 \\
P=0.686\end{array}$} & \multirow{2}{*}{$\begin{array}{c}x^{2}=0.000 \\
d f=1 \\
P=0.995\end{array}$} & \multirow[b]{2}{*}{$\begin{array}{l}Z=-1.221 \\
P=0.222\end{array}$} & \multirow[b]{2}{*}{$\begin{array}{l}Z=-1.156 \\
P=0.248\end{array}$} \\
\hline & Pleased & 13 & 40.6 & 23 & 76.7 & 14 & & & & & \\
\hline \multirow{3}{*}{$\begin{array}{l}\text { The first } \\
\text { prenatal } \\
\text { care visit }\end{array}$} & $\begin{array}{c}\text { First } \\
\text { trimester }\end{array}$ & 15 & 46.9 & 9 & 30.0 & 24 & 77.4 & $\begin{array}{c}x^{2}=12.78 \\
3\end{array}$ & $x^{2}=1.899$ & $x^{2}=1.099$ & $x^{2}=4.176$ \\
\hline & $\begin{array}{l}\text { Second } \\
\text { trimester }\end{array}$ & 16 & 50.0 & 20 & 66.7 & 6 & 19.4 & $d f=2$ & $d f=2$ & $d f=2$ & $d f=2$ \\
\hline & $\begin{array}{l}\text { Third } \\
\text { trimester }\end{array}$ & 1 & 3.1 & 1 & 3.3 & 1 & 3.2 & $P=0.002$ & $P=0.318$ & $P=0.448$ & $P=0.124$ \\
\hline \multirow{3}{*}{$\begin{array}{c}\text { Spouse's } \\
\text { idea about } \\
\text { BMF }\end{array}$} & $\begin{array}{l}\text { Strongly } \\
\text { agree }\end{array}$ & 10 & 31.3 & 4 & 13.3 & 7 & 22.6 & $x^{2}=6.547$ & $x^{2}=1.713$ & $x^{2}=1.430$ & $x^{2}=4.242$ \\
\hline & Agree & 22 & 68.8 & 21 & 70.0 & 23 & 74.2 & $d f=2$ & $d f=2$ & $d f=2$ & $d f=2$ \\
\hline & $\begin{array}{c}\text { No } \\
\text { comment }\end{array}$ & 0 & 0 & 5 & 16.7 & 1 & 3.2 & $P=0.038$ & $P=0.566$ & $P=0.589$ & $P=0.120$ \\
\hline \multirow{3}{*}{$\begin{array}{c}\text { Family's } \\
\text { idea about } \\
\text { BMF }\end{array}$} & $\begin{array}{l}\text { Strongly } \\
\text { agree }\end{array}$ & 8 & 25.0 & 1 & 3.3 & 4 & 12.9 & $x^{2}=7.661$ & $x^{2}=6.406$ & $x^{2}=1.019$ & $x^{2}=0.851$ \\
\hline & Agree & 24 & 75.0 & 27 & 90.0 & 26 & 83.9 & $d f=2$ & $d f=2$ & $d f=2$ & $d f=2$ \\
\hline & $\begin{array}{c}\text { No } \\
\text { comment }\end{array}$ & 0 & 0 & 2 & 6.7 & 1 & 3.2 & $P=0.022$ & $P=0.620$ & $P=0.394$ & $P=0.653$ \\
\hline \multirow{3}{*}{$\begin{array}{l}\text { Location of } \\
\text { prenatal } \\
\text { care }\end{array}$} & $\begin{array}{c}\text { Health care } \\
\text { centre }\end{array}$ & 4 & 12.5 & 10 & 33.3 & 14 & 45.2 & $x^{2}=7.048$ & $x^{2}=1.408$ & $x^{2}=1.038$ & $x^{2}=5.928$ \\
\hline & $\begin{array}{c}\text { Health care } \\
\text { centre+ } \\
\text { physician }\end{array}$ & 26 & 81.3 & 19 & 63.3 & 16 & 51.6 & $d f=2$ & $d f=2$ & $d f=2$ & $d f=2$ \\
\hline & $\begin{array}{c}\text { Health care+ } \\
\text { midwife }\end{array}$ & 2 & 6.3 & 1 & 3.3 & 1 & 3.2 & $P=0.029$ & $P=0.656$ & $P=0.749$ & $P=0.053$ \\
\hline \multirow{3}{*}{$\begin{array}{l}\text { Assistant } \\
\text { person in } \\
\text { caring } \\
\text { infant at } \\
\text { birth }\end{array}$} & Yes & 23 & 71.9 & 28 & 93.3 & 20 & 64.5 & $x^{2}=7.550$ & $x^{2}=2.173$ & $x^{2}=2.132$ & \\
\hline & No & 9 & 28.1 & 2 & 6.7 & 11 & 35.5 & $d f=2$ & $d f=1$ & $d f=1$ & $Z=-2.500$ \\
\hline & & & & & & & & $P=0.023$ & $P=0.237$ & $P=0.288$ & $P=0.012$ \\
\hline
\end{tabular}


Table 4. Mean of the duration of EBMF at 4 and 8 weeks after birth in assessed groups

\begin{tabular}{|c|c|c|c|c|c|c|c|c|c|c|c|c|}
\hline \multirow[t]{3}{*}{$\begin{array}{l}\text { The } \\
\text { duration } \\
\text { of EBMF } \\
\text { (day) }\end{array}$} & \multicolumn{4}{|c|}{ Total mothers in assessed groups } & \multicolumn{4}{|c|}{$\begin{array}{l}\text { Mothers who had no assistant help } \\
\text { in caring their children at after birth }\end{array}$} & \multicolumn{4}{|c|}{$\begin{array}{l}\text { Mothers who received an assistant } \\
\text { help in caring their children at after } \\
\text { birth }\end{array}$} \\
\hline & $\begin{array}{l}\text { Peer } \\
\text { Support }\end{array}$ & $\begin{array}{l}\text { Health } \\
\text { care } \\
\text { provider's } \\
\text { education }\end{array}$ & Control & P value & $\begin{array}{c}\text { Peer } \\
\text { Support }\end{array}$ & $\begin{array}{c}\text { Health } \\
\text { care } \\
\text { provider' } \\
\mathbf{s} \\
\text { educatio } \\
n\end{array}$ & Control & P value & $\begin{array}{c}\text { Peer } \\
\text { Support }\end{array}$ & $\begin{array}{l}\text { Health } \\
\text { care } \\
\text { provider' } \\
\mathbf{s} \\
\text { educatio } \\
n\end{array}$ & Control & $P$ value \\
\hline & $\begin{array}{c}\text { Mean } \pm \\
\text { SD }\end{array}$ & $\begin{array}{c}\text { Mean } \pm \\
\text { SD }\end{array}$ & $\begin{array}{c}\text { Mean } \pm \\
\text { SD }\end{array}$ & & $\begin{array}{c}\text { Mean } \pm \\
\text { SD }\end{array}$ & $\begin{array}{c}\text { Mean } \pm \\
\text { SD }\end{array}$ & $\begin{array}{c}\text { Mean } \pm \\
\text { SD }\end{array}$ & & $\begin{array}{c}\text { Mean } \pm \\
\text { SD }\end{array}$ & $\begin{array}{c}\text { Mean } \pm \\
\text { SD }\end{array}$ & $\begin{array}{c}\text { Mean } \pm \\
\text { SD }\end{array}$ & \\
\hline $\begin{array}{l}4 \text { wks } \\
\text { after } \\
\text { birth }\end{array}$ & $\begin{array}{l}13.0 \pm \\
12.65\end{array}$ & $\begin{array}{l}7.8 \pm \\
10.66\end{array}$ & $\begin{array}{l}6.5 \pm \\
9.47\end{array}$ & $P=0.056$ & $\begin{array}{l}5.9 \pm \\
10.04\end{array}$ & $\begin{array}{l}5.0 \pm \\
7.07\end{array}$ & $\begin{array}{l}5.8 \pm \\
9.53\end{array}$ & $P=0.993$ & $\begin{array}{l}15.7 \pm \\
12.67\end{array}$ & $\begin{array}{l}8.0 \pm \\
10.93\end{array}$ & $\begin{array}{l}7.0 \pm \\
9.67\end{array}$ & $P=0.020$ \\
\hline $\begin{array}{l}8 \text { wks } \\
\text { after } \\
\text { birth }\end{array}$ & $\begin{array}{l}21.7 \pm \pm \\
24.44\end{array}$ & $\begin{array}{c}10.10 \pm \\
16.23\end{array}$ & $\begin{array}{l}8.5 \pm \\
14.93\end{array}$ & $P=0.014$ & $\begin{array}{l}5.9 \pm \\
10.04\end{array}$ & $\begin{array}{l}5.0 \pm \\
7.07\end{array}$ & $\begin{array}{l}8.4 \pm \\
16.92\end{array}$ & $P=0.904$ & $\begin{array}{l}27.9 \pm \\
25.75\end{array}$ & $\begin{array}{r}10.5 \pm \\
16.70\end{array}$ & $\begin{array}{l}8.5 \pm \\
14.19\end{array}$ & $P=0.002$ \\
\hline$P$ value & $P=0.00$ & $P=0.088$ & $P=0.14$ & & $P=\underset{0^{*}}{1.00}$ & $P=\underset{0^{*}}{1.00}$ & $P=0.34$ & & $P=0.00$ & $P=\frac{0.08}{8}$ & $P=0.28$ & \\
\hline
\end{tabular}

${ }^{*}$ The SE of difference is 0 .

Table 5. Exclusive BMF rate at 4 and 8 weeks after birth in assessed groups

\begin{tabular}{|c|c|c|c|c|c|c|c|c|}
\hline \multicolumn{2}{|c|}{ Exclusive BMF } & \multicolumn{7}{|c|}{ Groups } \\
\hline & & \multicolumn{2}{|c|}{ Peer Support } & \multicolumn{2}{|c|}{$\begin{array}{c}\text { Health Care } \\
\text { Provider Education }\end{array}$} & \multicolumn{2}{|c|}{ Control } & \multirow[t]{2}{*}{ P values } \\
\hline & & Percent & $\mathbf{N}$ & Percent & $\mathbf{N}$ & Percent & $\mathbf{N}$ & \\
\hline \multirow[t]{3}{*}{4 wks after birth } & 3 & 9.7 & 5 & 16.7 & 11 & 34.4 & Yes & $X^{2}=6.294$ \\
\hline & 28 & 90.3 & 25 & 83.3 & 21 & 65.6 & NO & $d f=2$ \\
\hline & 100 & 31 & 30 & 100 & 32 & 100 & Total & $P=0.043$ \\
\hline \multirow[t]{3}{*}{8 wks after birth } & 2 & 6.5 & 2 & 6.7 & 9 & 28.1 & Yes & $X^{2}=8.120$ (Fisher exact) \\
\hline & 29 & 93.5 & 28 & 93.3 & 23 & 71.9 & NO & $d f=2$ \\
\hline & 31 & 100 & 30 & 100 & 32 & 100 & Total & $P=0.023$ \\
\hline \multicolumn{2}{|l|}{$P$ values } & \multicolumn{2}{|c|}{$P=0.500$} & \multicolumn{2}{|c|}{$P=0.250$} & \multicolumn{2}{|c|}{$P=1.000$} & \\
\hline
\end{tabular}


About $22.6 \%$ of the mothers of peer support group, $16.7 \%$ of the mothers of health care provider's education group, and $19.4 \%$ of the mothers of control group initiated breastfeeding within the first hour after birth. However, there were no significant differences between the groups $(p=0.879)$. The mean duration of exclusive BMF of total participants at 4 weeks after birth was $9.2 \pm$ 11.26 days, and the mean duration of exclusive BMF of total participants at 8 weeks was $13.5 \pm 19.81$ days. The three groups had no significant difference in terms of duration of exclusive BMF at 4 weeks $(P=0.056)$, but they had significant difference at 8 weeks $(P=0.014)$ (Table 4). The variable "assistant help in child care at and after birth to ward their family members" was heterogeneous in assessed groups. Also, it was a confounding variable on the duration of exclusive BMF. Therefore, its effect was assessed on the duration of exclusive BMF according to Table 4. The duration of exclusive BMF at 4 and 8 weeks had no significant difference in groups who did not receive assistant help to care their child at and after birth to ward their family members $(P=0.993$ and $P=0.904)$ (Table 4). The mentioned variable in groups who received assistant help to take care of their child at and after birth was $P=0.020$ and $P=0.002$, respectively (Table 4).

In this study, $20.4 \%$ of subjects had exclusive BMF at 4 weeks after birth. In peer support group - $34.4 \%$, in health care provider's education group - $16.7 \%$, and in control group $-9.7 \%$ of research subjects had exclusive BMF 4 weeks after birth. Fourteen percent of subjects had exclusive BMF at 8 weeks after birth. Chi square test showed that three groups had significant differences in the rate of exclusive BMF at 4 and 8 weeks after birth $(P=0.043$ and $P=0.023$ ) (Table 5).

Both peer support and health care provider's education had no significant difference in the rate of exclusive BMF at 4 weeks after birth $(P=0.111)$, but they significantly differ in terms of the rate of exclusive BMF at 8 weeks after birth $(P=0.027)$.

\section{Discussion}

These findings demonstrated that peer support and health care provider's education were similar in exclusive BMF duration. However, peer support was more effective than health care provider's education in increasing exclusive BMF rate. Compared with routine care, both groups of peer support and health care provider's education show some effect in extending the rate of exclusive breastfeeding. Assessing the effect of confounding variable "assistant help in child care at and after birth" on the duration of exclusive BMF showed that receiving peer support or training by health care providers did not increase the duration of exclusive BMF; but increased remarkably the rate of exclusive BMF.

Partners are particularly important because their approval means so much to a mother, and her partner is often her primary source of support. The baby's 
grandmothers are also very influential because mothers who have recently given birth rely on them for support and advice. To make breastfeeding successful, mothers need the support and encouragement of all of these people (Health and Services, 2011).

Dennis (2002) and Anderson (2005) concluded that peer support increases the rate of exclusive BMF that are in agreement with our result (Anderson et al., 2005; Dennis et al., 2002).

The findings of Meglio (2010) and Vari (2000) showed significant improvements in exclusive BMF duration resulting from peer support, whereas Graffy (2004), Muirhead (2006) and our research did not (Graffy et al., 2004; Meglio et al., 2010; Muirhead et al., 2006; Vari et al., 2000). Given the diversity of cultures and philosophies underpinning health service systems in different countries, it is unlikely that one generalised intervention will provide a magic bullet to increase breastfeeding (Hoddinott et al., 2011).

In addition, Vari examined breastfeeding status with the question "To provide feeding your infant, how long (the number of weeks) you use your milk?" Megilo investigated at the end of each week lactation status by the phone (Haroon et al., 2013; Vari et al., 2000), but in our study, daily feeding reports were used because that is closer to evaluation of infants' feeding pattern (Sheehan, 1999).

Belay (2013) and Artieta-Pinedo (2012) showed that education could increase exclusive BMF rates (Artieta-Pinedo et al., 2013; Belay and Haidar, 2013) which were consistent with the present study.

But Ansari (2014) and Sheehan (1999) concluded that breastfeeding education could increase the duration of exclusive BMF (Ansari et al., 2014; Sheehan, 1999) that was in contrast with the present study. Ansari utilised an integration method of peer education and professional education for intervention (Ansari et al., 2014) and Sheehan used peer education group in the presence of their spouses and in the education group by midwives. It seemed interventions that combine health professional and peer may be effective in increasing breastfeeding (Jolly et al., 2012). Moreover, women should make their spouse and family involved in deciding on BMF because their support affects initiating and continuing of BMF and to increase the duration of exclusive BMF (Esfahani Mm, 2009; Olang et al., 2009; Raine, 2003; Uchendu et al., 2009).

Su's study (2007) showed that exclusive BMF rate did not differ significantly between education and professional support groups (Su et al., 2007). Also, in the present study, the rate of exclusive BMF at 4 weeks after birth did not significantly differ between health care provider's education and peer support groups, but peer support increased the rate of exclusive BMF at 8 weeks more than health care provider's education. In the present study, peer supporters emphasised to each mother that they are available and dedicated to help them with their breastfeeding needs and challenges. The supportive actions of the 
peer supporters vary according to the mother's needs at the moment and peer supporters' assessment of the situation.

Because of sampling selection in health care centres, the effect of some prenatal factors, such as drugs during delivery and neonatal Apgar score, were not assessed on exclusive BMF. However, some factors such as mode of delivery, interval between birth and infant's first contact with the mother, interval between birth and the first baby BMF, duration of the first BMF, mother's satisfaction with delivery, and postpartum complications were controlled as much as possible.

\section{Conclusion}

In this study, education and peer support increased the number of women who fed exclusively with breast milk, to continue exclusive breastfeeding, and to increase its duration. The help of family is more important than education and peer support. Therefore, it is suggested that families are educated about the importance of supporting and helping lactating mothers. All women should be offered education and peer support to breastfeed their babies to increase the exclusive breastfeeding rate. But to continue exclusive breastfeeding, and increase its duration, the help of family is more important than education and peer support. Support that is only offered reactively, in which women are expected to initiate the contact, is unlikely to be effective; women should be offered ongoing support so they can predict that support will be available. Support should be tailored to the needs of the setting and the population group. The strength of the study is that it was conducted in 3 groups by multistage sampling method, and then the groups were randomly allocated into peer support, health care provider's education, and control groups. The generalisation of our findings to other breastfeeding women is limited by the small sample size.

\section{Abbreviations}

WHO: World Health Organization; BMF: breast milk feeding, ANOVA: The analysis of variance

\section{Acknowledgment}

This study was financially supported by a grant given to second author by the Vice Chancellery of Research of Mashhad University of Medical Sciences and Nursing and Midwifery School, Iran. So we appreciate the Vice Chancellery. 


\section{Biomedical \\ Research \& Therapy}

ISSN: 2198-4093

\section{Author Contributions}

Asieh Moudi contributed to study design, data acquisition and analysis, and wrote the manuscript. Mahin Tafazoli contributed to write and edited the manuscript. Hasan Boskabadi to reviewed and edited the manuscript for intellectual content. Saeed Ebrahimzadeh contributed to data analysis and reviewed and edited the manuscript for intellectual content. Hamid Salehiniya designed the study, analyzed data, and wrote the manuscript. All authors gave final approval of the version to be published. Asieh Moudi is the guarantor of this work and, as such, had full access to all the data in the study and takes responsibility for the integrity of the data and the accuracy of the data analysis. All authors reed the final version of article. 


\section{References}

Anderson, A.K., Damio, G., Young, S., Chapman, D.J., and Pérez-Escamilla, R. (2005). A randomized trial assessing the efficacy of peer counseling on exclusive breastfeeding in a predominantly Latina low-income community. Archives of Pediatrics \& Adolescent Medicine 159, 836-841.

Andrade S, A.M., Battersy Sue, Buchanan Phyll, Cowbrough Kathy, Duncan James, Dykes Fiona (2008). A peer-support programme for women who breastfeed -Commissioning guide Implementing NICE guidance. In: INSTITUTEFORHEALTHANDCLINICALEXCELLENCE, N (ed) England.

Ansari, S., Abedi, P., Hasanpoor, S., and Bani, S. (2014). The Effect of Interventional Program on Breastfeeding Self-Efficacy and Duration of Exclusive Breastfeeding in Pregnant Women in Ahvaz, Iran. International Scholarly Research Notices 2014.

Artieta-Pinedo, I., Paz-Pascual, C., Grandes, G., Bacigalupe, A., Payo, J., and Montoya, I. (2013). Antenatal education and breastfeeding in a cohort of primiparas. Journal of advanced nursing 69, 1607-1617.

Belay, S., and Haidar, J. (2013). Effect of prenatal education on breastfeeding initiation and exclusive breast feeding rate in selected health institutions of Hawassa city, the capital of Snnpr, Ethiopia. East African Journal of Public Health 10.

Chung, M., Raman, G., Trikalinos, T., Lau, J., and Ip, S. (2008). Interventions in primary care to promote breastfeeding: an evidence review for the US Preventive Services Task Force. Annals of Internal Medicine 149, 565-582.

Dennis, C.-L. (2003). Peer support within a health care context: a concept analysis. International journal of nursing studies 40, 321-332.

Dennis, C.-L., Hodnett, E., Gallop, R., and Chalmers, B. (2002). The effect of peer support on breast-feeding duration among primiparous women: a randomized controlled trial. Canadian Medical Association Journal 166, 21-28.

Dennis, C.-L.E. (1999). A randomized controlled trial evaluating the effect of peer (mother-to-mother) support on breastfeeding duration among primiparous women (National Library of Canada= Bibliothèque nationale du Canada).

Dennis, C.L., and Kingston, D. (2008). A systematic review of telephone support for women during pregnancy and the early postpartum period. Journal of Obstetric, Gynecologic, \& Neonatal Nursing 37, 301-314.

Dyson, L., McCormick, F., and Renfrew, M.J. (2005). Interventions for promoting the initiation of breastfeeding. Cochrane Database Syst Rev 2.

Esfahani Mm, O.B., Bahrami M, Parsay S, Halimi Asl Aa, Khatami Gh, et al. (2009). Training series promoting of breastfeeding tehran. Unicef.

Graffy, J., Taylor, J., Williams, A., and Eldridge, S. (2004). Randomised controlled trial of support from volunteer counsellors for mothers considering breast feeding. BMJ 328, 26.

Haroon, S., Das, J.K., Salam, R.A., Imdad, A., and Bhutta, Z.A. (2013). Breastfeeding promotion interventions and breastfeeding practices: a systematic review. BMC public health $13,1$.

Health, U.D.o., and Services, H. (2011). The Surgeon General's call to action to support breastfeeding. 
Hoddinott, P., Seyara, R., and Marais, D. (2011). Global evidence synthesis and UK idiosyncrasy: why have recent UK trials had no significant effects on breastfeeding rates? Maternal \& Child Nutrition 7, 221-227.

Imdad, A., Yakoob, M.Y., and Bhutta, Z.A. (2011). Effect of breastfeeding promotion interventions on breastfeeding rates, with special focus on developing countries. BMC public health 11, 1.

Jolly, K., Ingram, L., Khan, K.S., Deeks, J.J., Freemantle, N., and MacArthur, C. (2012). Systematic review of peer support for breastfeeding continuation: metaregression analysis of the effect of setting, intensity, and timing. BMJ 344, d8287.

Lumbiganon, P., Martis, R., Laopaiboon, M., Festin, M.R., Ho, J.J., and Hakimi, M. (2012). Antenatal breastfeeding education for increasing breastfeeding duration. The Cochrane Library.

Mead, S., Hilton, D., and Curtis, L. (2001). Peer support: a theoretical perspective. Psychiatric rehabilitation journal 25, 134.

Meglio, G.D., McDermott, M., and Klein, J. (2010). A randomized controlled trial of telephone peer support's influence on breastfeeding duration in adolescent mothers. Breastfeeding Medicine 5, 41-47.

Mickens, A.D. (2008). Infant feeding decisions among pregnant Black WIC participants and the role of peer support (ProQuest).

Motlaq Me, B.S., Saadvandiyan S (2013). Portrait of national program to promote breastfeeding in Islamic Republic of Iran. Past-Present-Furture, Fuzhan graphic.

Muirhead, P.E., Butcher, G., Rankin, J., and Munley, A. (2006). The effect of a programme of organised and supervised peer support on the initiation and duration of breastfeeding: a randomised trial. Br J Gen Pract 56, 191-197.

Muller, C., Newburn, M., Wise, P., Dodds, R., and Bhavnani, V. (2009). NCT breastfeeding peer support project. London: NCT.

Najem, B. (2011). Dhia Al-Deen L. Breast Feeding Problems in Primipara Mothers in Early Postnatal Period. Iraqi J Comm Med 24.

Olang, B., Farivar, K., Heidarzadeh, A., Strandvik, B., and Yngve, A. (2009). Breastfeeding in Iran: prevalence, duration and current recommendations. International breastfeeding journal 4, 1.

Owais Ahmad M, S.U., Kalsoom U, Imran M, Hadi U (2012). Effect of antenatal counseling on exclusive breastfeeding. J Ayub Med Coll Abbottabad 24, 116-119.

Palda, V.A., Guise, J.-M., and Wathen, C.N. (2004). Interventions to promote breastfeeding: applying the evidence in clinical practice. Canadian Medical Association Journal 170, 976-978.

Persad, M.D., and Mensinger, J.L. (2008). Maternal breastfeeding attitudes: association with breastfeeding intent and socio-demographics among urban primiparas. Journal of community health 33, 53-60.

Raine, P. (2003). Promoting breast-feeding in a deprived area: the influence of a peer support initiative. Health \& social care in the community 11, 463-469.

Rossman, B. (2007). Breastfeeding peer counselors in the United States: helping to build a culture and tradition of breastfeeding. Journal of Midwifery \& Women's Health 52, 631-637.

Sheehan, A. (1999). A comparison of two methods of antenatal breast-feeding education. Midwifery 15, 274-282. 
Sikorski, J., Renfrew, M.J., Pindoria, S., and Wade, A. (2003). Support for breastfeeding mothers: a systematic review. Paediatric and perinatal epidemiology 17, 407-417.

Su, L.-L., Chong, Y.-S., Chan, Y.-H., Chan, Y.-S., Fok, D., Tun, K.-T., Ng, F.S., and Rauff, M. (2007). Antenatal education and postnatal support strategies for improving rates of exclusive breast feeding: randomised controlled trial. Bmj 335, 596.

Translators-Group (2008). in translation Breastfeeding hand book for physicians, American Academy Of Pediatrics \& The American College Of Obestetricians and Gynecologists.

Uchendu, U., Ikefuna, A., and Emodi, I. (2009). Factors associated with exclusive breastfeeding among mothers seen at the University of Nigeria Teaching Hospital. South African Journal of Child Health 3.

Vari, P.M., Camburn, J., and Henly, S.J. (2000). Professionally mediated peer support and early breastfeeding success. The Journal of perinatal education 9, 22-30. 